\title{
Commentary
}

\section{Early career investigator highlight: April}

\author{
Maria Luisa Tataranno ${ }^{1}$
}

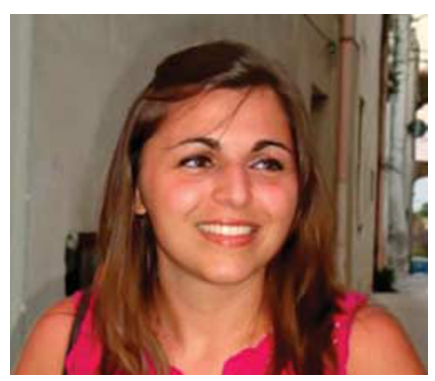

grew up in Bernalda, a small village in the South of Italy,

with my parents and two brothers. I attended the School of Medicine at the University of Siena, where I graduated magna cum laude in 2009. Afterward, I entered the residency program in Pediatrics at the University of Siena, where I graduated cum laude in 2015. I am currently working as a fellow of neonatal neurology at the Wilhelmina Children Hospital in Utrecht. I was awarded with the ESPR early investigator exchange program award and I am involved in setting up a study evaluating the relationship between brain function and structure in preterm infants.

During my medical training, I decided to perform two clinical internship in Pediatrics, one in Mexico and one in
Brazil. These wonderful and intense experiences lit up my enthusiasm and passion for Pediatrics. I realized that every sick child in the world deserves the best possible care and I wanted to do my utmost to live up to that ideal. In the first years of my residency training, I discovered my interest for research and I started working on a project about oxidative stress biormarkers and their relation to brain injury in preterm infants, under the influence of Professor Giuseppe Buonocore. Owing to this project, I had the opportunity to move to The Netherlands, at the Department of Neonatology of the Wilhelmina Children Hospital, for a research fellowship, under the supervision of Professor Manon Benders and Professor Linda deVries. In The Netherlands, I had the chance to start a $\mathrm{PhD}$ project about early biomarkers of brain development and to improve my knowledge on neonatal neurology. I am grateful to all the preterm infants I met in the last years, the infinite strength I perceived in such small human beings, taught me to never give up.

My advice is to keep your enthusiasm on and always challenge yourself. Believe in your dreams and have the courage to make them come true! The road will be uphill but it's worth it.

Disclosure: The authors declare no conflict of interest. 